\title{
Delayed Development of Primary Biliary Cirrhosis in a Patient with Acute Glomerulonephritis: A Possible Pitfall of a Self-limiting Disease
}

\author{
Atsushi Miki ${ }^{1}$, Shin-ichi Takeda ${ }^{1}$, Norio Isoda ${ }^{2}$, Hisashi Yamamoto ${ }^{1}$, Mari Okada ${ }^{1}$, \\ Saki Nakagawa ${ }^{1}$, Toshimi Imai ${ }^{1}$, Ryuta Sato ${ }^{1}$, Osamu Saito ${ }^{1}$ and Daisuke Nagata ${ }^{1}$
}

\begin{abstract}
Acute poststreptococcal glomerulonephritis (APSGN) is a well-established disease. Although various immune responses are thought to be involved in the pathogenesis of APSGN, the disease has a self-limiting nature in clinical practice, despite the presence of severe acute symptoms. We herein report the case of a 78year-old woman with APSGN who developed primary biliary cirrhosis (PBC) after achieving remission of renal manifestations, including anasarca and elevation of serum creatinine, indicating that persistent alterations in the immune system can cause extrarenal disorders. This case provides insights into the appropriate clinical management of ASPGN and pathogenesis of PBC.
\end{abstract}

Key words: acute glomerulonephritis, primary biliary cirrhosis, immunological disorders

(Intern Med 54: 1885-1889, 2015)

(DOI: 10.2169/internalmedicine.54.3634)

\section{Introduction}

Acute glomerulonephritis (AGN) is a well-defined renal disease predominantly caused by nephritogenic streptococcal strains (acute poststreptococcal glomerulonephritis; APSGN). The clinical manifestations of AGN are usually self-limiting, although a variety of immune responses are involved, including immune complex formation, complement activation, cellular immunity and autoimmune reactivity (1). Primary biliary cirrhosis (PBC) is a chronic autoimmune disease of the liver characterized by biliary duct destruction and may be associated with other autoimmune diseases, such as Sjögren's syndrome (2), interstitial lung disease (2) and limited cutaneous scleroderma (3). PBC may also be associated with diverse renal disorders, including membranous nephropathy $(4,5)$, antineutrophil cytoplasmic autoantibody (ANCA)-associated rapidly progressive glomerulonephritis (6), antiglomerular basement membrane (GBM) disease (7) and membranoproliferative glomerulonephritis-like lesions (8). However, to our knowledge, an association be- tween PBC and AGN has not been documented. We herein report the case of a 78-year-old woman who was diagnosed with PBC after achieving clinical remission of AGN. The findings of this case provide a platform to reconsider the clinical and immunological aspects of AGN.

\section{Case Report}

A 78-year-old woman was referred to our hospital in August 2012 for anasarca accompanied by orthopnea, oliguresis and anemia. She had received antihypertensive treatment with daily doses of $5 \mathrm{mg}$ of amlodipine, $50 \mathrm{mg}$ of losartan and $12.5 \mathrm{mg}$ of hydrochlorothiazide, although she had otherwise been free from medical problems, including hyperlipidemia. The rapid development of renal impairment [serum creatinine $(\mathrm{Cr}): 2.54 \mathrm{mg} / \mathrm{dL}$ ] and abnormal urinalysis results (microscopic hematuria, marked proteinuria and cylindruria) were the principal findings on laboratory tests. The serum Cr level had been normal $(0.69 \mathrm{mg} / \mathrm{dL})$ when she visited her personal physician nine days before the referral.

The patient was immediately hospitalized and underwent

${ }^{1}$ Division of Nephrology, Department of Medicine, Jichi Medical University, Japan and ${ }^{2}$ Division of Gastroenterology and Hepatology, Department of Medicine, Jichi Medical University, Japan

Received for publication July 7, 2014; Accepted for publication November 30, 2014

Correspondence to Dr. Shin-ichi Takeda, takeshin@jichi.ac.jp 


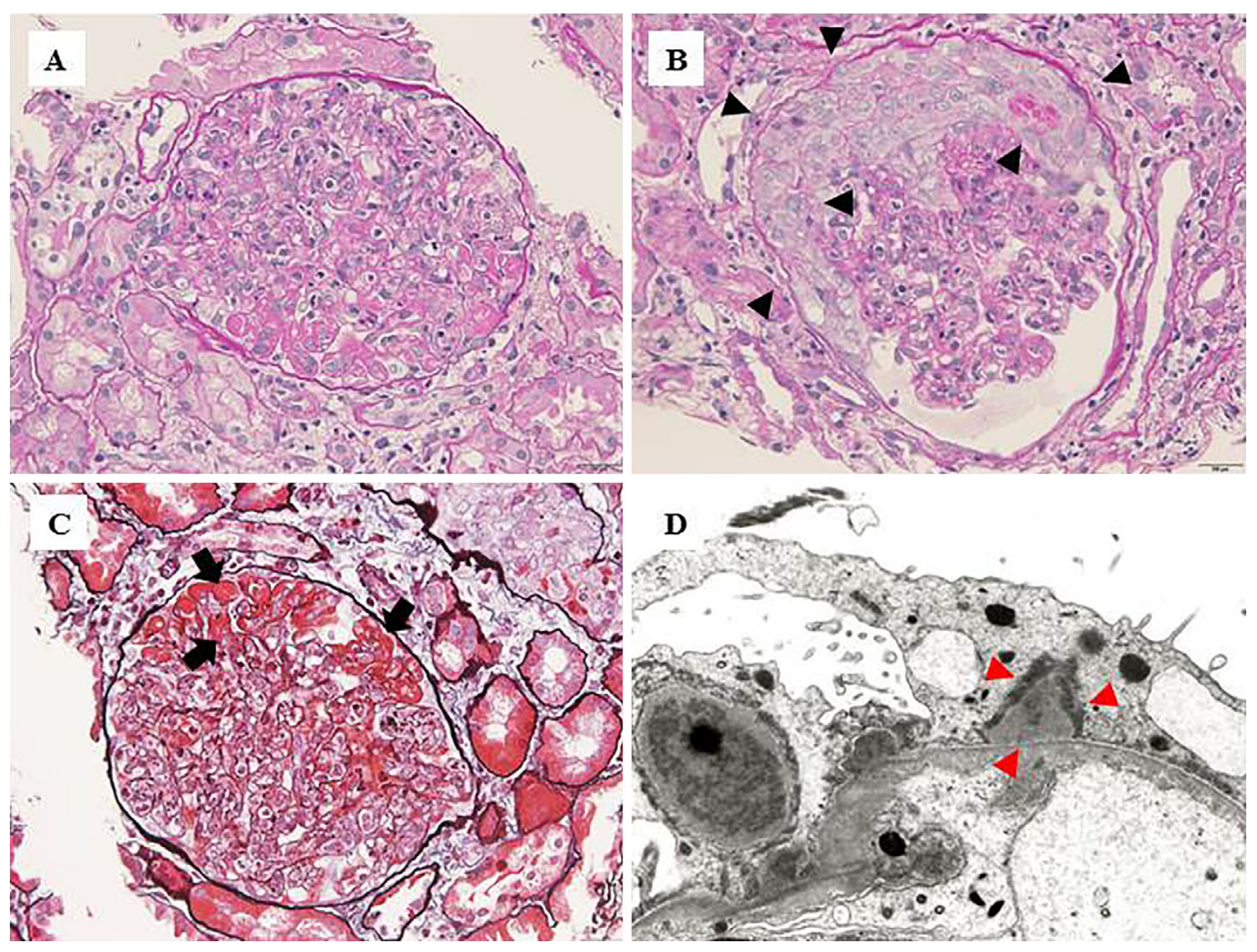

Figure 1. Representative photomicrographs of the renal biopsy specimens. (A) Marked cellular proliferation of enlarged glomeruli, which resulted in capillary obstruction, was the principal finding. (B) Cellular crescent formation (black arrowheads) was observed in five of 13 glomeruli. (C) Redstained deposits (arrows) were scattered. (D) An ultrastructural study delineated subepithelial humpshaped electron dense deposits (red arrowheads). Periodic acid-Schiff (A, B) and Masson-Trichrome (C) staining. Original magnification: $\times 400(A-C)$ and $\times 8,000$ (D).

a renal biopsy the next day. Endo- and extracapillary cellular proliferation, especially that of neutrophils in the glomeruli (Fig. 1A), with cellular crescent formation in five of 13 glomeruli (Fig. 1B) and Masson-stained deposits (Fig. 1C), were prominent features on light microscopy. The results of immunofluorescence (IF) were as follows: $\operatorname{IgG}( \pm) ; \operatorname{IgA}(+)$; $\operatorname{IgM}(-)$; $\mathrm{C} 3 \mathrm{c}(++)$; $\mathrm{C} 4(-)$; $\mathrm{C} 1 \mathrm{q}(-)$; and fibrinogen(-). Electron microscopy delineated hump-shaped subepithelial electron dense deposits (Fig. 1D). In addition, group A streptococcus was detected on a throat swab using an enzyme immunoassay, and findings for serological markers were positive for antistreptolysin (ASO; 1,060 U/mL) and antistreptokinase (ASK; 10,240x). Therefore, the patient was diagnosed with AGN, likely associated with antecedent infection with group A streptococcus, despite a lack of overt infectious symptoms.

In contrast to the severe histological changes, the patient's renal function gradually recovered (serum Cr level: $0.68 \mathrm{mg} /$ dL on day 29; Fig. 2) with only symptomatic treatment, including the restriction of sodium intake and the administration of diuretics and amoxicillin $(500 \mathrm{mg} / \mathrm{day})$. Similarly, signs of excess water retention, including bilateral pleural effusion (Fig. 3A) and subcutaneous edema, disappeared, resulting in a marked decrease in body weight from 48.8 to $36.6 \mathrm{~kg}$. Incidentally, a compression fracture of the lumbar vertebrae was noted, consistent with the patient's complaint of lower back pain. Therefore, relatively long-term hospitalization was required, after which she was transferred to another facility for rehabilitation in late October. A cultivation survey was performed under computed tomography (CT) guidance; however, the pathogen was not detected in the lesion.

In contrast to the improvement in the renal disorder, elevation of serum biliary enzymes developed over time (Fig. 2B). Shortly after the patient returned to our hospital in late November, the serum levels of alkaline phosphatase (ALP) and gamma-glutamyltransferase ( $\gamma$-GTP) increased to 1,061 and $150 \mathrm{mU} / \mathrm{mL}$, respectively, whereas those of aspartate aminotransferase and alanine aminotransferase remained in the normal range (26 and $15 \mathrm{mU} / \mathrm{mL}$, respectively). The patient had no history of alcohol consumption or drug treatment that could have been regarded as causative. No spaceoccupying lesions such as the formation of stones which potentially cause obstructive jaundice were evident in the hepatobiliary tract on CT (Fig. 3B) or ultrasonography. A positive result for antimitochondrial (AMA) M2 antibodies (index up to 564) was noted, although other serum-specific markers, including antinuclear antibodies and anti-smooth muscle antibodies, were all negative. A careful examination by a hepatologist led to a final diagnosis of $\mathrm{PBC}$, based on 

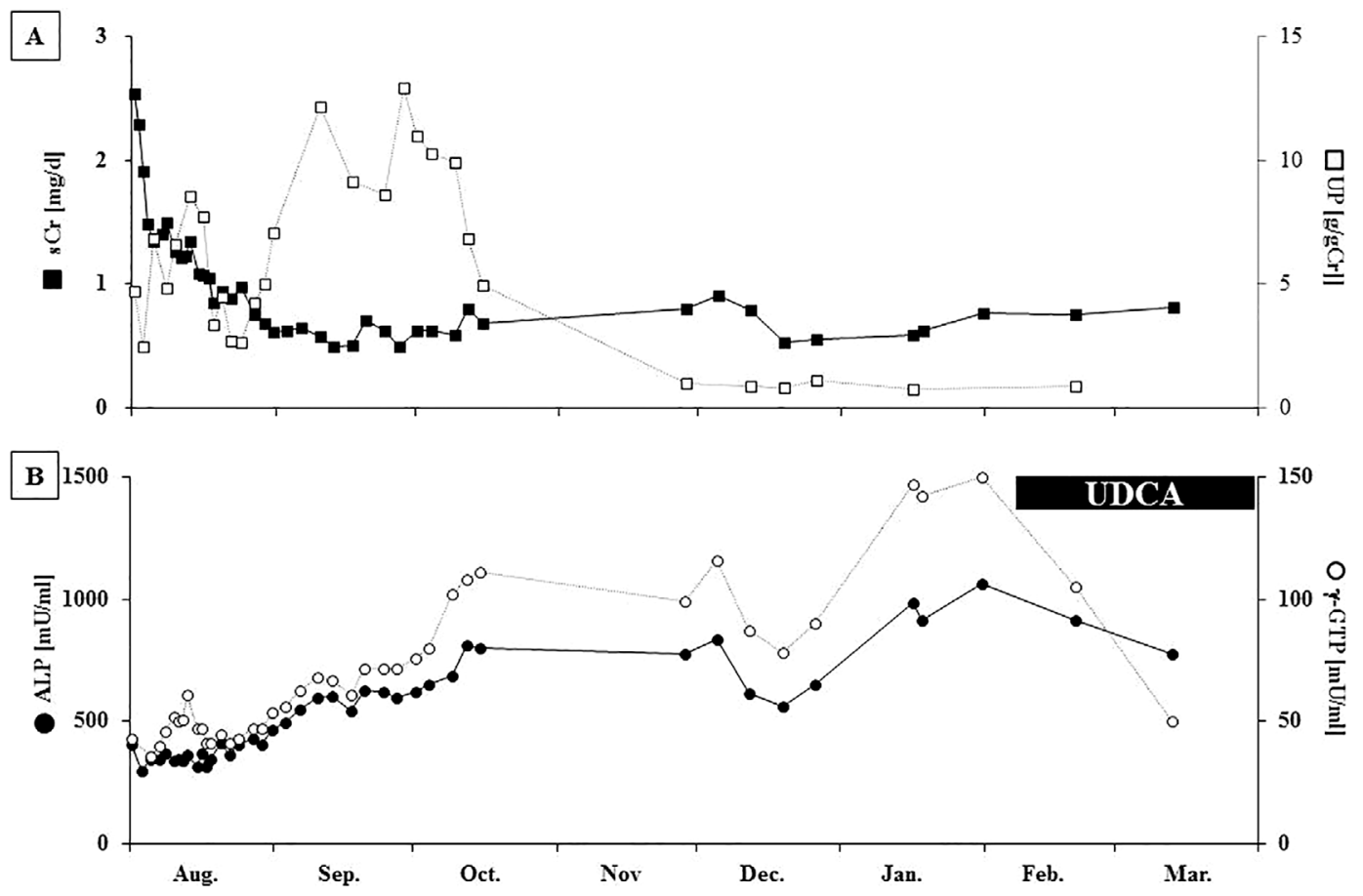

Figure 2. Serial changes in the levels of (A) renal markers and (B) serum biliary enzymes. sCr: serum creatinine, UP: urinary protein, ALP: alkaline phosphatase, $\gamma$-GTP: gamma-glutamyltransferase, UDCA: ursodeoxycholic acid. closed squares: $\mathrm{sCr}$, open squares: UP, closed circles: ALP, open circles: $\gamma$-GTP
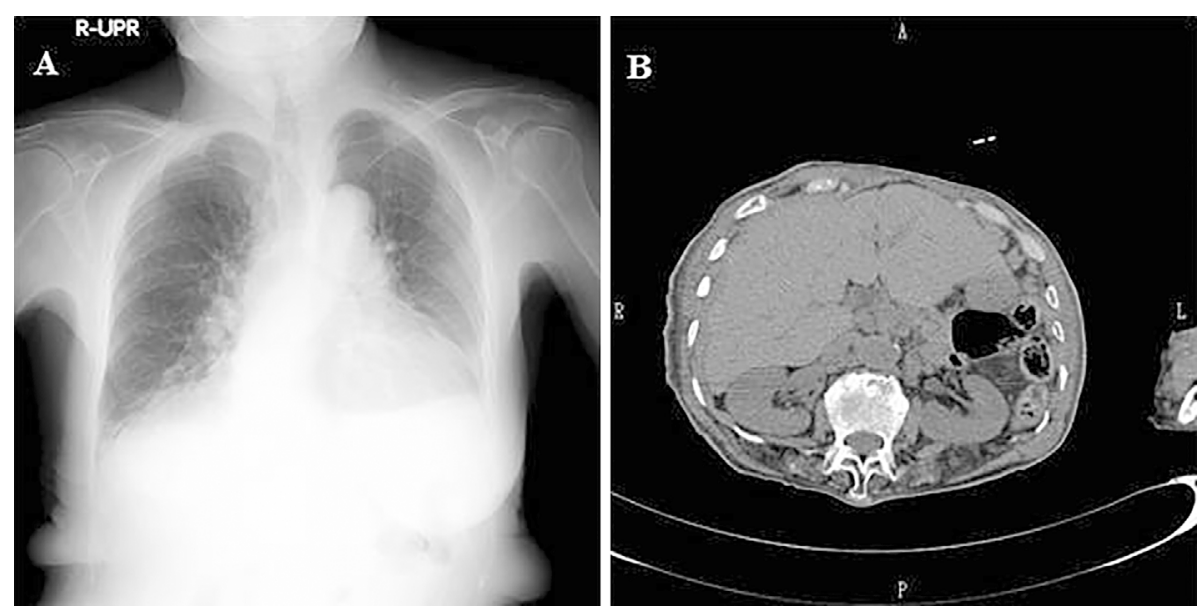

Figure 3. Radiological images. (A) A chest X-ray demonstrating cardiac enlargement and bilateral pleural effusion at the time of admission. (B) Computed tomography of the abdomen showing no significant findings in the liver.

the Japanese clinical practice guidelines for PBC 2012 issued by the study group commissioned by the Ministry of Health, Labour and Welfare of Japan, an official publication written in Japanese. Incidentally, serum markers for systemic autoimmune diseases, including anti-SS-A/Ro antibodies, anti-SS-B/La antibodies and anti-citrullinated peptide antibodies, were negative, and no elevation of serum IgM was observed $(176 \mathrm{mg} / \mathrm{dL})$. The patient did not develop any physical symptoms associated with $\mathrm{PBC}$, such as dermal pruritus. Following the administration of ursodeoxycholic acid at a dose of $200 \mathrm{mg}$ thrice daily, the serum ALP and $\gamma$ GTP levels markedly decreased to 559 and $50 \mathrm{mU} / \mathrm{mL}$, respectively.

\section{Discussion}

In this case, the patient was diagnosed with AGN and subsequently developed PBC, despite exhibiting an improvement in her renal function. The renal biopsy findings of diffuse cellular proliferation in the glomeruli, predominant 
glomerular deposition of $\mathrm{C} 3$ detected on IF, a unique ultrastructure (humps) and positive results for streptococcal infection were consistent with the typical features of APSGN.

The precise incidence of nephrotic syndrome in adult cases of AGN has not been reported in recent years, although estimates in the older literature range from $10 \%$ to $30 \%(9,10)$. In our patient, heavy proteinuria (up to 6.357 $\mathrm{g} /$ day) persisted after observing a recovery in the renal function (Cr clearance: from 25.8 to $61.2 \mathrm{~mL} / \mathrm{min}$ ) and then was eventually attenuated (as of December, $0.819 \mathrm{~g} / \mathrm{gCr}$ ). Hence, the serious renal manifestations resolved within a couple of months, consistent with the self-limiting nature of APSGN. It is generally agreed that immune complexes are the 'toxic bodies' thought to be responsible for the symptoms noted in cases of poststreptococcal glomerulonephritis (1), although diverse immune responses, including autoimmune reactivity (1), are also involved in the pathogenesis of this renal disorder.

PBC is an autoimmune disease of the liver that is serologically characterized by the presence of antimitochondrial antibodies, which most commonly react with the E2 subunit of the pyruvate dehydrogenase complex (PDCE2) (11). The important role of autoimmunity in $\mathrm{PBC}$ is reflected in the many reports regarding the associations of this disorder with other autoimmune diseases, including Sjögren's syndrome (2), interstitial lung disease (2), limited cutaneous scleroderma (3) and rheumatoid arthritis (12). Patients exhibiting various renal diseases, such as membranous nephropathy $(4,5)$, ANCA-associated rapidly progressive glomerulonephritis (6), antiglomerular basement membrane (GBM) disease (7) and membranoproliferative glomerulonephritis-like lesions (8), have also been reported; however, to our knowledge, this is the first description of a case of PBC associated with ASPGN.

Molecular mimicry is a widely proposed mechanism for the initiation of autoimmunity in patients with PBC and several candidates have been suggested as causative agents, including bacteria, viruses and chemicals in the environment $(11,13,14)$. Bacteria, particularly Escherichia coli (E. coli), have attracted the most attention due to the elevated incidence of urinary tract infections in patients with PBC $(13,14)$ and highly conserved nature of mitochondrial autoantigens (11). In fact, antibodies to the human pyruvate dehydrogenase complex react well against the E. coli pyruvate dehydrogenase complex (11). Novosphingobium aromaticivorans, a ubiquitous xenobiotic-metabolizing bacterium, has also been proposed as a candidate for the induction of $\mathrm{PBC}$, as sera obtained from patients with $\mathrm{PBC}$ react with two lipoylated bacterial proteins derived from $N$. aromaticivorans at titers up to $10^{-6}$, which is approximately 100- to 1,000-fold higher than that against E. coli (15). Therefore, antecedent infection may be an important process in the development of PBC associated with ASPGN.

Streptococcus intermedius, a Gram-positive streptococcal strain, may also play a key role in the pathogenesis of $\mathrm{PBC}$, with the possible involvement of histone-like DNA-binding proteins (16). The potential nephritogenicity of a histonelike protein of streptococci has been proposed (17), although the role of this protein in the onset of nephritis remains speculative due to the lack of information on antibodies in patients exhibiting sequelae and streptococcal histone localization in the glomeruli in cases of glomerulonephritis (1).

Collectively, these results support our hypothesis that the two disorders (AGN and PBC) observed in our patient may share, in part, a common pathophysiological mechanism induced by bacterial infection. We conclude that the presence of protracted immune disorders may underlie the development of PBC, even in patients with APSGN in clinical remission. From the perspective of clinical management, longterm follow-up is required with careful attention to the possible subsequent development of extrarenal autoimmune diseases.

\section{The authors state that they have no Conflict of Interest (COI).}

\section{Acknowledgement}

We would like to thank Yuko Suda, Yukari Hoshino and Aiko Oashi for their excellent assistance with this report.

\section{References}

1. Rodríguez-Iturbe B, Batsford S. Pathogenesis of poststreptococcal glomerulonephritis a century after Clemens von Pirquet. Kidney Int 71: 1094-1104, 2007.

2. Liu B, Zhang FC, Zhang ZL, Zhang W, Gao LX. Interstitial lung disease and Sjögren's syndrome in primary biliary cirrhosis: a causal or casual association? Clin Rheumatol 27: 1299-1306, 2008.

3. Mayo MJ, Jenkins RN, Combes B, Lipsky PE. Association of clonally expanded $\mathrm{T}$ cells with the syndrome of primary biliary cirrhosis and limited scleroderma. Hepatology 29: 1635-1642, 1999.

4. Vlassopoulos D, Divari E, Savva S, et al. Membranous glomerulonephritis associated with primary biliary cirrhosis. Nephrol Dial Transplant 13: 459-461, 1998.

5. Sakamaki Y, Hayashi M, Wakino S, et al. A case of membranous nephropathy with primary biliary cirrhosis and cyclosporineinduced remission. Intern Med 50: 233-238, 2011.

6. Nakamura T, Kawagoe Y, Ueda Y, Koide H. Antineutrophil cytoplasmic autoantibody-associated rapidly progressive glomerulonephritis in a patient with primary biliary cirrhosis. Am J Med Sci 328: 176-179, 2004.

7. Marriott JB, Oliveira DB. Antimitochondrial autoantibodies in anti-glomerular basement membrane disease. Clin Exp Immunol 93: 259-264, 1993.

8. Koike K, Utsunomiya Y, Ito Y, et al. A case of glomerulopathy showing podocytic infolding in association with Sjögren's syndrome and primary biliary cirrhosis. Clin Exp Nephrol 12: 489493, 2008.

9. Hinglais N, Garcia-Torres R, Kleinknecht D. Long-term prognosis in acute glomerulonephritis. The predictive value of early clinical and pathological features observed in 65 patients. Am J Med 56: 52-60, 1974.

10. Baldwin DS, Gluck MC, Schacht RG, Gallo G. The long-term course of poststreptococcal glomerulonephritis. Ann Intern Med 80: $342-358,1974$.

11. Kaplan MM, Gershwin ME. Primary biliary cirrhosis. N Engl J Med 253: 1261-1273, 2005.

12. Caramella C, Avouac J, Sogni P, Puéchal X, Kahan A, Allanore Y. 
Association between rheumatoid arthritis and primary biliary cirrhosis. Joint Bone Spine 74: 279-281, 2007.

13. Parikh-Patel A, Gold EB, Worman H, Krivy KE, Gershwin ME. Risk factors for primary biliary cirrhosis in a cohort of patients from the united states. Hepatology 33: 16-21, 2001.

14. Gershwin ME, Selmi C, Worman HJ, et al. Risk factors and comorbidities in primary biliary cirrhosis: a controlled interviewbased study of 1032 patients. Hepatology 42: 1194-1202, 2005.

15. Selmi C, Balkwill DL, Invernizzi $P$, et al. Patients with primary biliary cirrhosis react against a ubiquitous xenobiotic-metabolizing bacterium. Hepatology 38: 1250-1257, 2003.

16. Haruta I, Kikuchi K, Hashimoto E, et al. A possible role of histone-like DNA-binding protein of Streptococcus intermedius in the pathogenesis of bile duct damage in primary biliary cirrhosis. Clin Immunol 127: 245-251, 2008.

17. Stinson MW, McLaughlin R, Choi SH, Juarez ZE, Barnard J. Streptococcal histone-like protein: primary structure of $h l p A$ and protein binding to lipoteichoic acid and epithelial cells. Infect Immun 66: 259-265, 1998 .

(C) 2015 The Japanese Society of Internal Medicine http://www.naika.or.jp/imonline/index.html 